\title{
Characterization of the Immune Response Induced by a Commercially Available Inactivated Bluetongue Virus Serotype 1 Vaccine in Sheep
}

\author{
Ana Cristina Pérez de Diego, ${ }^{1}$ Pedro José Sánchez-Cordón, ${ }^{2}$ Ana Isabel de las Heras, ${ }^{1}$ \\ and José Manuel Sánchez-Vizcaíno ${ }^{1}$ \\ ${ }^{1}$ VISAVET Health Surveillance Centre and Animal Health Department, Veterinary Faculty, Complutense University of Madrid, \\ Avenida Puerta de Hierro s/n, 28040 Madrid, Spain \\ ${ }^{2}$ Department of Comparative Pathology, Veterinary Faculty, University of Córdoba, Animal Health Building, Rabanales Campus, \\ 14014 Córdoba, Spain
}

Correspondence should be addressed to Ana Cristina Pérez de Diego, anacristina@sanidadanimal.info

Received 18 October 2011; Accepted 22 December 2011

Academic Editors: E. Carrillo and K. E. Kester

Copyright (C) 2012 Ana Cristina Pérez de Diego et al. This is an open access article distributed under the Creative Commons Attribution License, which permits unrestricted use, distribution, and reproduction in any medium, provided the original work is properly cited.

\begin{abstract}
The protective immune response generated by a commercial monovalent inactivated vaccine against bluetongue virus serotype 1 (BTV1) was studied. Five sheep were vaccinated, boost-vaccinated, and then challenged against BTV1 ALG/2006. RT-PCR did not detect viremia at any time during the experiment. Except a temperature increase observed after the initial and boost vaccinations, no clinical signs or lesions were observed. A specific and protective antibody response checked by ELISA was induced after vaccination and boost vaccination. This specific antibody response was associated with a significant increase in B lymphocytes confirmed by flow cytometry, while significant increases were not observed in T lymphocyte subpopulations $\left(\mathrm{CD} 4^{+}, \mathrm{CD}^{+}\right.$, and $\left.\mathrm{WC1}^{+}\right)$, $\mathrm{CD} 25^{+}$regulatory cells, or CD14 ${ }^{+}$monocytes. After challenge with BTV1, the antibody response was much higher than during the boost vaccination period, and it was associated with a significant increase in B lymphocytes, CD $14^{+}$monocytes, $\mathrm{CD}_{2} 5^{+}$regulatory cells, and $\mathrm{CD}^{+}$cytotoxic T lymphocytes.
\end{abstract}

\section{Introduction}

Bluetongue virus (BTV), a member of the Orbivirus genus in the Reoviridae family [1], shows considerable genetic and antigenic variability, with at least 25 different serotypes characterized to date $[2,3]$. These serotypes do not confer crossprotective immunity, which means that specific vaccines must be developed for each serotype [4].

Vaccination has proven very effective in BTV control and eradication strategies [5,6]. A wide range of vaccines, based on either inactivated or modified live virus, are available against different BTV serotypes [7]. Inactivated vaccines are considered safer than vaccines based on modified live virus because they do not allow the possibility of viral replication. Therefore, they are useful for avoiding virus circulation among susceptible species $[8,9]$. Indeed, inactivated vaccines have already been used successfully in field trials, and they are the vaccines most recommended by EU authorities $[8,10]$.

Several inactivated BTV vaccines have been shown to confer protection mainly by inducing production of neutralizing antibodies [11-14]. These antibodies protect primarily against homologous serotypes, and they appear ineffective at cross-protecting against heterologous serotypes $[15,16]$. Some studies reveal that cell-mediated immunity could play an important role [17] when vaccinating with individual antigens [18], or concretely just in some sheep [19]. Also, inactivated vaccines have been shown to protect against BTV in the absence of neutralizing antibodies $[4,20]$, but it is well known that the main effective response against BT is capable to generate neutralizing antibodies [11].

Evaluating the cell-mediated immunity in animals vaccinated against BTV could provide valuable information for 
TABLE 1: Antibodies used to analyze PBMC populations by flow cytometry.

\begin{tabular}{|c|c|c|c|c|c|}
\hline $\begin{array}{l}\text { Primary and } \\
\text { secondary } \\
\text { antibodies }\end{array}$ & Specificity & Ig isotype & $\begin{array}{l}\text { Amount per } \\
\text { tube }(\mu \mathrm{g})\end{array}$ & Source & Reference \\
\hline $\begin{array}{l}\text { Anti-sheep B } \\
\text { lymphocytes }\end{array}$ & B lymphocytes & $\operatorname{IgM}$ & 2 & VMRD & BAQ44A \\
\hline Anti-sheep CD4 & T helper lymphocytes & $\operatorname{IgG}_{1}$ & 2 & VMRD & 17D1 \\
\hline Anti-sheep CD8 & Cytotoxic T lymphocytes & $\mathrm{IgG}_{1}$ & 2 & VMRD & САСТ $80 \mathrm{C}$ \\
\hline Anti-sheep WC1 & $\gamma \delta$ subset of T lymphocytes & $\operatorname{IgG}_{1}$ & 2 & VMRD & IL-A29 \\
\hline Anti-sheep CD25 & IL-2 receptor $\alpha$-chain & $\operatorname{IgG}_{1}$ & 2 & VMRD & CACT116A \\
\hline Anti-sheep CD14 & Monocytes & $\operatorname{IgG}_{1}$ & 2 & VMRD & CAM36A \\
\hline $\begin{array}{l}\text { FITC-conjugated } \\
\text { anti-mouse IgG1 } \\
(\gamma 1)\end{array}$ & Mouse IgG1 $(\gamma 1)$ & - & 0.4 & Invitrogen & P-21129 \\
\hline $\begin{array}{l}\text { PE-conjugated } \\
\text { anti-mouse IgM }\end{array}$ & Mouse IgM & - & 0.4 & Sigma-Aldrich & F-9259 \\
\hline
\end{tabular}

assessing and improving the efficacy of BTV vaccines. To that end, the present study aimed to examine, in vivo, the cellular and humoral immune response generated by a commercial monovalent, inactivated vaccine against BTV serotype 1 in Merino sheep.

\section{Materials and Methods}

All procedures were carried out in accordance with the Code of Practice for Housing and Care of Animals Used in Scientific Procedures, approved by the European Economic Community in 1986 (86/609/EEC) and amended by European Commission Directive 2003/65/EC. The procedures were also approved by the Animal Experimental Committee of Complutense University of Madrid.

2.1. Animals. Five female Merino sheep of 9-10 months old and negative for antigens or antibodies against BTV were housed in Biosafety Level 3 facilities (VISAVET, Complutense University of Madrid).

2.2. Vaccine. A commercial inactivated vaccine against BTV serotype 1 was used (Zulvac1, Fort Dodge Veterinaria SA). The active component per dose ( $2 \mathrm{~mL}$ ) was BTV-1/ALG2006/ $01 \mathrm{E} 1 \geq 10^{6.4} \mathrm{TCID}_{50}$. This vaccine contains adjuvants such as Quillaia bark, with the primary adjuvant being hydrated aluminum hydroxide.

2.3. Vaccination, Boost Vaccination, and BTV Challenge. Vaccination was carried out SC on day 0 of the experiment. Booster vaccination was performed by the same route on day 20 . In both cases, the vaccine dose was $2 \mathrm{~mL}$ as recommended by manufacturer. On day 48 , all animals were challenged with $1 \mathrm{~mL}$ of BTV1 ALG/2006 at a virus title of $1.9 \times 10^{6}$ $\mathrm{TCID}_{50}$ in BHK cells. The challenge inoculum contained $1.9 \times 10^{6} \mathrm{TCID}_{50}$ (kindly provided by CISA-INIA), and it was administered intravenously into the jugular vein. On day 68 , animals were euthanized.
2.4. Temperature Monitoring, Clinical Survey, and Necropsy. Rectal temperature was measured on day 0 prior to vaccination, as well as on various days until the end of the trial on day 68. On each of these occasions, clinical signs were scored using the system described by Perrin et al. [21].

2.5. Sample Collection for Serology and BTV RNA Extraction. Serum samples were collected on day 0 prior to vaccination, as well as on days $3,14,16,20,21,23,26,35,42,48,51,53$, $54,57,58,61,62$, and 68 . Samples were analyzed by a doublerecognition ELISA (Ingezim BTV DR 12.BTV.K0, Ingenasa) according to the manufacturer's instructions. Antibody response was measured as optical density.

Samples of EDTA blood were collected on day 0 prior to vaccination, as well as on days $3,20,21,23,42,48,51,53,54$, $57,58,61,62$ and 68. RNA was extracted from the samples using the NucleoSpin RNA II kit (Macherey-Nagel). The presence of BTV RNA was assessed using real-time RT-PCR (RT-qPCR) targeting BTV segment 5. Briefly, this RT-qPCR was able to detect up to 100 RNA copies. The relationship between the $\mathrm{Ct}$ and the copy number was linear between 17 and 33 cycles, which correspond to $1 \times 10^{8}$ and $1 \times 10^{3}$ copies, respectively. The RT-qPCR had an efficiency of $96 \%$, and it was associated with an $\mathrm{R}^{2}$ of 0.99 . The RT-qPCR was able to detect the mRNA in all of the 128 biological samples from sheep, goats, and cattle tested [22]. This could be supposed as a high sensitivity close to $100 \%$. In our study, the negative controls were not template controls, while positive controls where sample from experimentally infected animals, and their Cts were between 20 and 25.

\subsection{Flow Cytometry Analysis of Peripheral Blood Mononuclear} Cells. EDTA blood samples were collected on day 0 prior to vaccination, as well as on days $3,14,16,20,21,23,26,35,42$, $48,51,53,54,57,58,61,62$, and 68 . Flow cytometry using an FACS scan cytometer (Becton Dickinson) was used to detect different populations of peripheral blood mononuclear cells (PBMCs) (Table 1). 


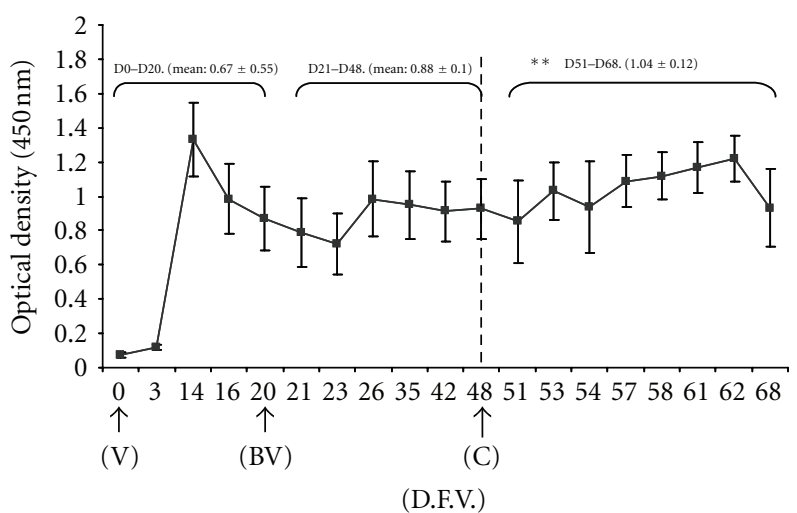

(a)

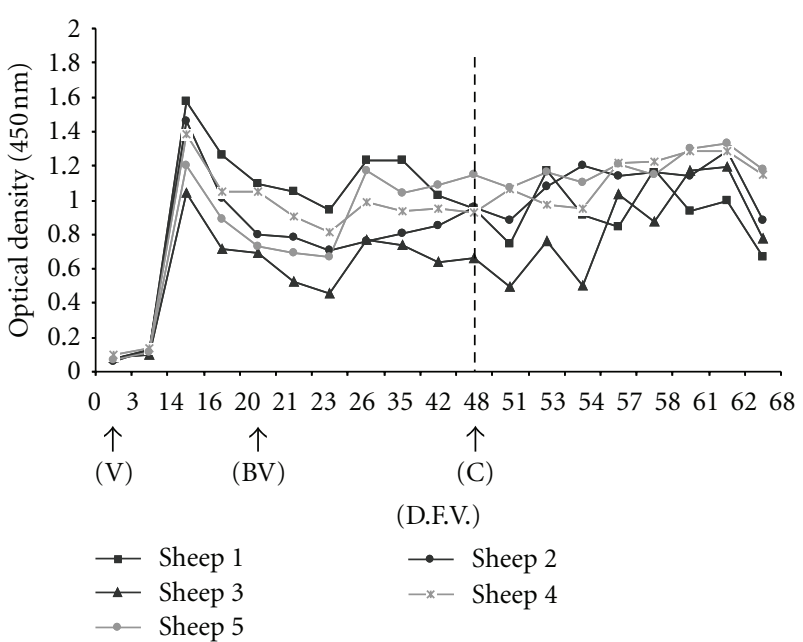

(b)

FIgURE 1: (a) Antibody response in serum samples (mean optical density \pm SD) measured by ELISA during the experiment. The threshold below which a response was considered negative was defined as $15 \%$ of the positive control optical density. Thus, samples with an optical density $>0.252$ were considered positive. The mean value after boost vaccination was significantly different from that after challenge $(* * P \leq$ 0.05; Mann-Whitney $U$ test for nonparametric distributions). (b) Individual measurements of antibody response. Abbreviations: $\mathrm{V}$, day of first vaccination; DFV, day after first vaccination; BV, day of boost vaccination; $\mathrm{C}$, day of challenge.

2.7. Statistical Analysis. Data were analyzed using GraphPad InStat 3.0 and IBM SPSS Statistics 19. Percentages of PBMC subpopulations $\left(\mathrm{CD}^{+}, \mathrm{CD}^{+}, \mathrm{WC}^{+}, \mathrm{CD} 25^{+}, \mathrm{B}\right.$ lymphocytes, and $\left.\mathrm{CD} 14^{+}\right)$are reported as mean \pm standard deviation (SD). Differences between the percentages of PBMC populations at different times and the values prior to vaccination on day 0 were analyzed by repeated-measures ANOVA with the Huynh-Feldt correction.

Optical density results from ELISA testing of serum samples are reported as mean \pm SD. Differences among mean optical density values after vaccination (days 0-20), after boost vaccination (days 21-48), and after challenge (days 5168) were analyzed using the Mann-Whitney $U$ test for nonparametric distributions.

For all comparisons, differences for which $P<0.05$ were considered significant.

\section{Results}

3.1. Temperature, Clinical Signs, and Lesions. Hyperthermia (rectal temperature higher than $40^{\circ} \mathrm{C}$ ) was detected in three sheep on day 1 after vaccination and in three sheep on day 21 after boost vaccination. After challenge, however, no increase in temperature was detected in any animal.

No BTV clinical signs were observed during the experiment. Moreover, necropsy failed to detect gross lesions characteristic of BTV infection. Histopathology confirmed the absence of microscopic lesions characteristic of BTV.

3.2. Determination of Antibody Response by ELISA. A specific antibody response against BTV was detected in all vaccinated sheep from day 14 through the end of the experiment (Figures 1(a) and 1(b)). Antibody levels peaked on day 14, decreasing moderately thereafter. Antibody levels began to rise again from day 26 , and the levels remained relatively constant until day 51. From that point until day 62, the levels increased again, showing a slight decrease only in the final stage of the study.

Mean values of antibody response were compared for the periods after vaccination (days $0-20$ ), after boost vaccination (days 21-48), and after challenge (days 51-68). No significant differences were observed between antibody levels after vaccination $(0.67 \pm 0.55)$ and after boost vaccination $(0.88 \pm$ 0.1 ). After challenge, however, the antibody level increased significantly to $1.04 \pm 0.12$ (Figure $1(\mathrm{a})$ ).

3.3. BTV RNA Detection by RT-PCR. No viral genome was detected in the animals at any time in the study.

\subsection{Analysis of PBMC Populations}

3.4.1. $\mathrm{CD}^{+}{ }^{+} \mathrm{CD}^{+} \mathrm{T}$ lymphocytes represented $32.87 \%$ of PBMC before vaccination. Between days 14 and 21, the proportion of $\mathrm{CD}^{+}$cells significantly declined, with the minimum value of $21.7 \%$ occurring on day 14 (Figures 2 (a) and 2(b)). Subsequently, the proportion returned to its prevaccination level. After challenge, the level decreased significantly again between days 51 and 53, reaching $22.7 \%$ on day 53 . The level then returned to prevaccination values for the rest of the trial.

3.4.2. $\mathrm{CD}^{+}$. The mean percentage of $\mathrm{CD} 8^{+} \mathrm{T}$ lymphocytes prior to vaccination (day 0) was $9.89 \%$ (Figures 2(c) and $2(d))$. This percentage did not vary significantly after vaccination or boost vaccination. It increased from day 57 , nine days after challenge, and peaked between days 62 and 68 . 


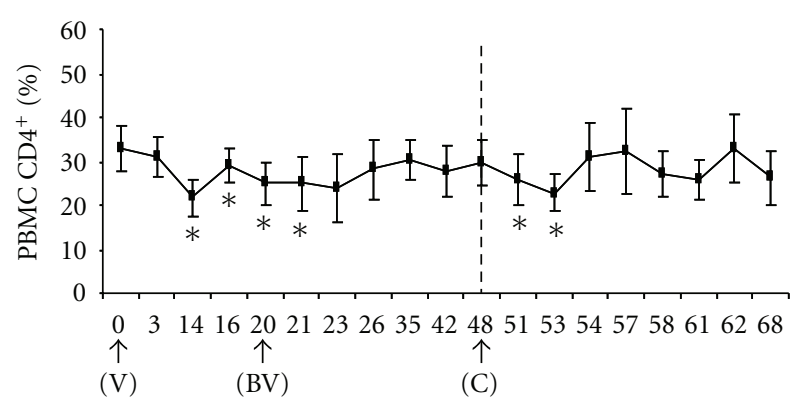

(D.F.V.)

(a)

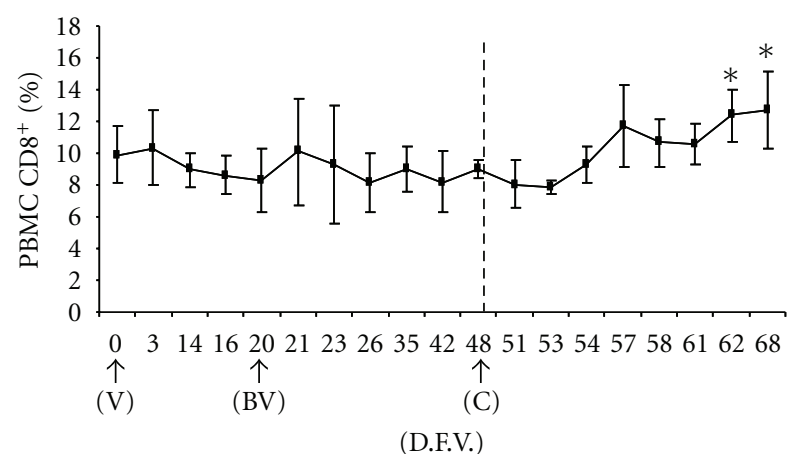

(c)

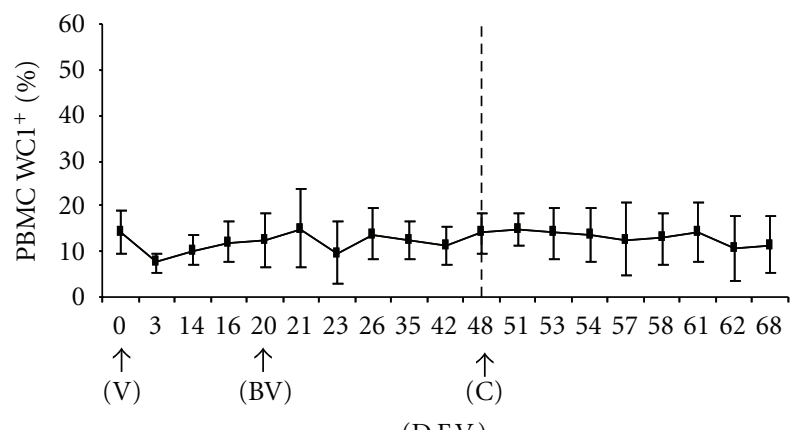

(D.F.V.)

(e)

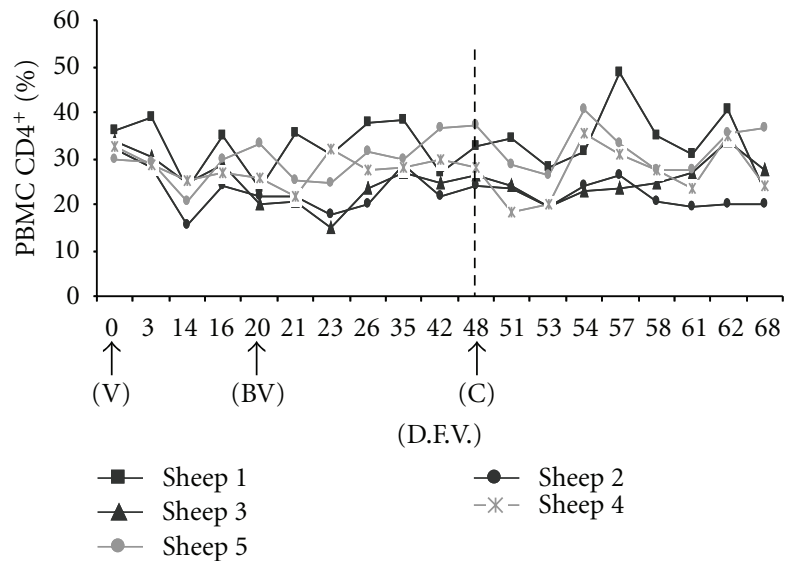

(b)

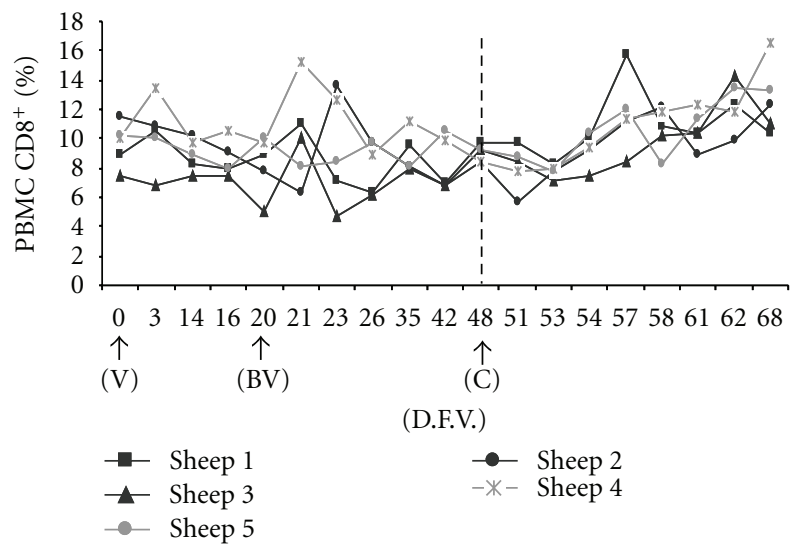

(d)

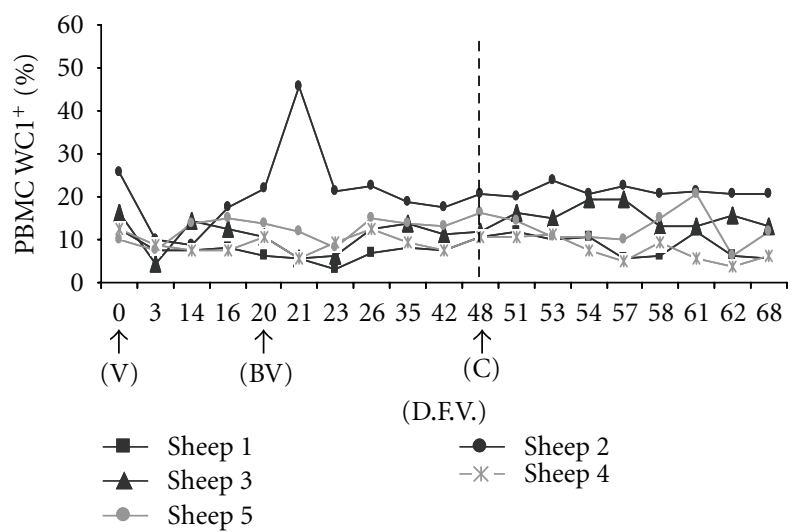

(f)

Figure 2: Mean percentages $( \pm \mathrm{SD})$ and individual percentages of PBMC populations labeled by antibodies against CD4 ${ }^{+}(\mathrm{a}, \mathrm{b}), \mathrm{CD}^{+}(\mathrm{c}$, d), and $\mathrm{WCl}^{+}(\mathrm{e}, \mathrm{f})$ throughout the experiment. ${ }^{*}$ is statistically significant difference $(P \leq 0.05)$ from prevaccination value on day 0 , based on ANOVA with the Huynh-Feldt correction. Abbreviations: V, day of first vaccination; DFV, day after first vaccination; BV, day of boost vaccination; $\mathrm{C}$, day of challenge.

3.4.3. $\mathrm{WC1}^{+}$. The percentage of $\gamma \delta \mathrm{T}$ lymphocytes labeled by the anti- $\mathrm{WC1}^{+}$antibody did not vary significantly from the prevaccination value of $14.28 \%$ (Figures $2(\mathrm{e})$ and $2(\mathrm{f})$ ).

3.4.4. $C D 25^{+}$. The percentage of $\mathrm{CD} 25^{+}$cells increased slightly, but not significantly, from a pre-vaccination value of
$7.44 \%$ to $14.18 \%$ on day 14 (Figure $3(\mathrm{a})$ ). This percentage did not change significantly after boost vaccination. After challenge, however, all five animals showed an increase in the proportion of $\mathrm{CD}_{2} 5^{+}$cells. For example, by day 51, the level in sheep 4 and sheep 5 had increased, respectively, to $24.2 \%$ and $31.3 \%$ (Figure 3(b)). The level increased significantly 

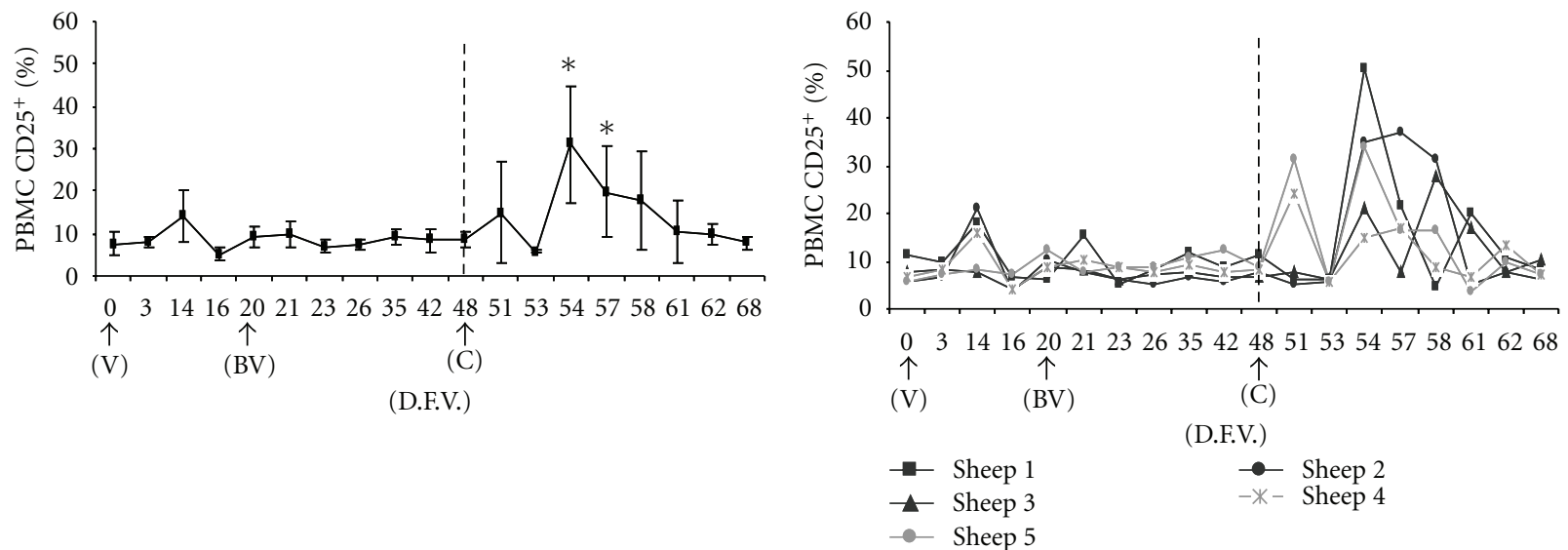

(a)
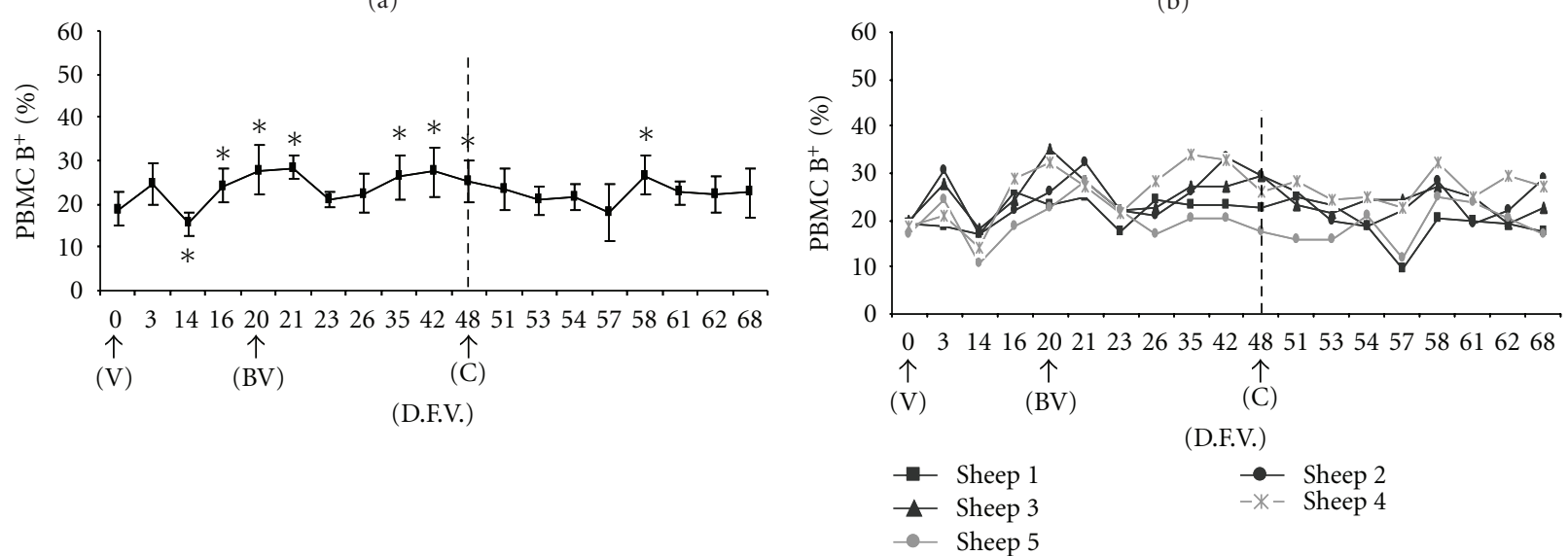

(c)
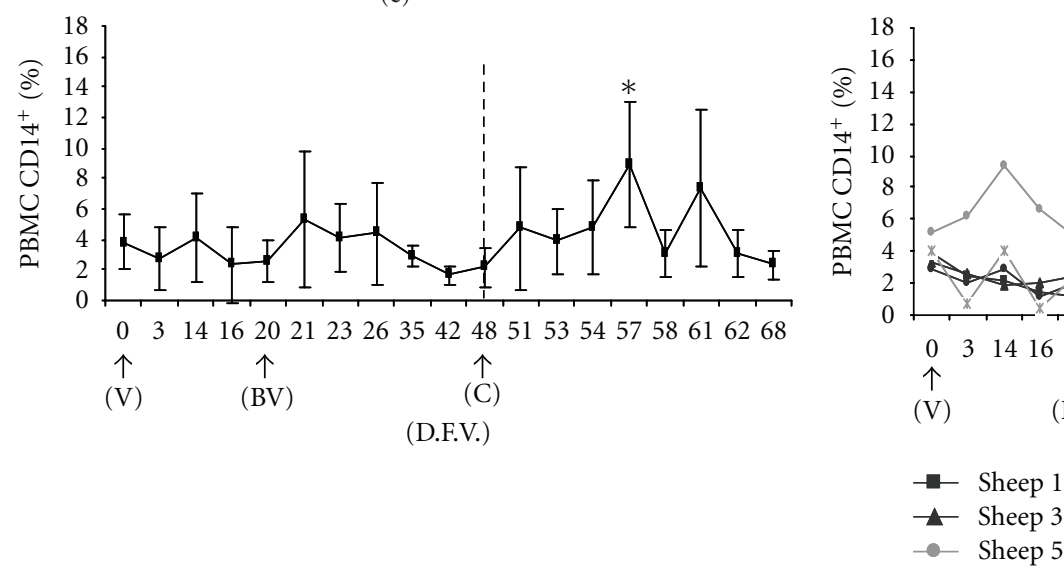

(d)

(e)

(f)

FIgURE 3: Mean percentages $\left( \pm\right.$ SD) and individual percentages of PBMC populations labeled by antibodies against $\mathrm{CD}^{+} 5^{+}(\mathrm{a}, \mathrm{b}), \mathrm{B}^{+}$cells $(c, d)$, and $\mathrm{CD}_{1} 4^{+}(\mathrm{e}, \mathrm{f})$ throughout the experiment. ${ }^{*}$ is statistically significant difference $(P \leq 0.05)$ from the mean pre-vaccination value on day 0, based on ANOVA with the Huynh-Feldt correction. Abbreviations: V, day of first vaccination; DFV, day after first vaccination; BV, day of boost vaccination; $\mathrm{C}$, day of challenge.

again between days 54 and 57, peaking on day 54 (31.2\%). Subsequently, the level decreased progressively and returned to pre-vaccination values at the end of the experiment.

3.4.5. B Lymphocytes. The percentage of B cells decreased significantly after vaccination, with the lowest level of $15.4 \%$ occurring on day 14 (Figures $3(\mathrm{c})$ and $3(\mathrm{~d})$ ). The level signifi- cantly increased thereafter between days 16 and 21, and again after boost vaccination between days 35 and 48. After challenge, the percentage varied slightly, showing a significant increase on day 58 .

3.4.6. $C D 14^{+}$. The percentage of monocytes labeled by the anti-CD $14^{+}$antibody did not change significantly from its 
pre-vaccination value of $3.85 \%$ after vaccination or boost vaccination (Figures 3(e) and 3(f)). After challenge, however, the percentage increased significantly, reaching $10.28 \%$ on day 57. Subsequently, it decreased until it returned to prevaccination values on days 62 and 68 . After challenge, all animals showed an increase followed by a marked decrease. This response occurred on different dates for different animals, though in all cases the levels reached similar values.

\section{Discussion}

The inactivated vaccine against BTV serotype 1 (Zulvac1, Fort Dodge Veterinaria SA) induced an effective immune response in all vaccinated sheep. Challenge virus was not detected in blood by RT-PCR even at 20 days after inoculation. Except for a temperature increase observed in most animals after the vaccination and boost vaccination, no clinical signs or lesions characteristic of BTV infection were observed.

The temperature increase observed in most animals after vaccination and boost vaccination may reflect activation/ stimulation of the immune system. Similar increases were observed after administration of inactivated vaccines against different serotypes of BTV $[23,24]$. However, such a temperature increase was not observed in sheep after vaccination or revaccination with vaccines containing virus-like particles [25]. These vaccines lack genetic material and so are nonreplicative; instead, they contain complexes of structural proteins (VP2, VP3, VP5, and VP7) [26]. Therefore, even though inactivated BTV vaccines do not contain live virus, they seem to have a greater ability to stimulate the immune system from a very early stage due to the presence of potent adjuvants.

After subcutaneous administration of inactivated vaccines against BTV, the presence of viral RNA in blood should not be detected $[11,27]$. Moreover, such vaccines prevent viral replication after challenge with homologous virus [28, 29]. Our results showed the absence of virus in blood after both vaccinations as well as after challenge with BTV serotype 1 . These findings suggest that this vaccine may prevent both virus dissemination and disease spread from vaccinated animals. Therefore, in the presence of vector-borne BTV serotype 1 , the inactivated vaccine not only prevents virus replication but also effectively induces a protective immune response. The specific protection conferred by these vaccines appears to relate to the key role played by structural protein VP2 in stimulating protective immunity mediated by $\mathrm{T}$ and $\mathrm{B}$ cells $[18,30]$. However, the immunological mechanisms behind the protection observed in vaccinated animals, including the possible role of the cellular immune response, remains unclear.

At 14 days after vaccination, a specific antibody response against BTV was observed in all vaccinated sheep, and it persisted through the end of the experiment. This antibody response was shown to be the main factor in protecting sheep against BTV serotype 1 . Our results are in agreement with previous studies $[8,11]$, wherein the specific antibodies detected by ELISA after administration of inactivated BTV vaccines in sheep were considered to be neutralizing anti- bodies with the ability to protect against the virus. Nevertheless, how antibodies against BTV neutralize virus in vivo remains unclear, despite attempts to demonstrate antibodydependent cellular cytotoxicity $[17,31]$.

The potential role of the cellular immune response during BTV infection and after vaccination is not fully understood $[4,18,20,32]$. In the present study, the specific antibody response detected in sheep after vaccination and boost vaccination against BTV serotype 1 was not associated with either a significant increase in T lymphocyte subpopulations $\left(\mathrm{CD}^{+}, \mathrm{CD}^{+}\right.$, and $\left.\mathrm{WC}^{+}\right)$or in $\mathrm{CD} 25^{+}$regulatory cells. Moreover, significant changes in the percentage of CD14 $4^{+}$ monocytes were not observed. These results are in agreement with previous studies of inactivated vaccines against BTV serotype 1 in sheep [33].

The lack of cell-mediated immunity after vaccination and boost vaccination in our experiment could be attributed to different components of the vaccine, in which inactivated virus was mixed with an aluminum-based adjuvant. These adjuvants delay the elimination of antigens after vaccine administration, prolonging the antigenic stimulus. These adjuvants also promote antibody response, even though they have little stimulatory effect on cell-mediated responses [34-36]. This inability to stimulate a strong cell-mediated response, together with the diversity of responses by antigenpresenting cells following exposure to live or killed viruses in vaccines $[37,38]$, may explain the moderate participation of cell-mediated response after vaccination and boost vaccination, as well as the absence of significant changes in the proportions of these immune cell populations.

On the other hand, B cells can recognize most antigens without prior processing, and certain antigens can provoke antibody formation in the absence of helper $\mathrm{T}$ cells, providing sufficient signal for B cell proliferation and differentiation into antibody-producing plasma cells $[39,40]$. This may explain why the significant increase in B lymphocytes observed after vaccination and boost vaccination in the present study was associated with an increase in specific antibodies against BTV serotype 1 .

After challenge, viral genome was not detected in vaccinated sheep, confirming specific protection induced by antibody response. In fact, antibody response after challenge was significantly higher than after boost vaccination, and this increase was associated with a significant increase in CD14 ${ }^{+}$ monocytes, $\mathrm{CD} 25^{+}$cells, B lymphocytes, and $\mathrm{CD}^{+} \mathrm{T}$ lymphocytes. Thus, challenge with BTV serotype 1 significantly increased the levels of CD $14^{+}$monocytes and $\mathrm{CD} 25^{+}$regulatory cells. CD14 has been defined as a central molecule in antigen recognition and cellular interactions, where it plays a key role in monocyte-mediated T-cell activation $[18,41]$. In addition to dendritic cells [32], monocyte macrophages play an important role in antigen presentation and virus spread during BTV infection $[42,43]$. CD25 has been defined as a low-affinity receptor for IL-2 that is expressed mainly on $\mathrm{T}$ cells activated by interaction with antigens $[44,45]$. Thus, the increase in $\mathrm{CD} 14^{+}$monocytes and $\mathrm{CD} 25^{+}$regulatory cells observed after challenge with BTV serotype 1 may costimulate B cells, allowing their activation, proliferation, and differentiation into antibody-producing plasma cells. 
Finally, after challenge with BTV serotype 1, an increase in $\mathrm{CD}^{+}{ }^{+}$lymphocytes was observed, which became significant toward the end of the trial. Similar increases in CD8 ${ }^{+}$ T lymphocytes and the cytokine IL-2 in association with an increase in CD25 expression have been described after challenge of sheep vaccinated against BTV serotype 1 [33]. Such increases have also been observed during experimental infections $[31,32,46]$. Thus, the activation and proliferation of $\mathrm{CD}^{+} \mathrm{T}$ lymphocytes, which play a key role in the Th1 response dominated by cytotoxic $\mathrm{T}$ cells, may also be associated with the increase in $\mathrm{CD} 14^{+}$monocytes and $\mathrm{CD} 25^{+}$regulatory cells observed after challenge.

\section{Conclusions}

Collectively, these results demonstrate that a specific and protective antibody response was induced after vaccination and boost vaccination of sheep with an inactivated vaccine against BTV serotype 1 (Zulvac1, Fort Dodge Veterinaria SA). This response was associated with a significant increase in B lymphocytes. However, significant increases were not observed in T lymphocyte subpopulations $\left(\mathrm{CD} 4^{+}, \mathrm{CD}^{+}\right.$, and $\left.\mathrm{WC}^{+}\right), \mathrm{CD}_{2} 5^{+}$regulatory cells, or $\mathrm{CD} 14^{+}$monocytes. After challenge with BTV serotype 1, antibody response significantly increased over the level observed after boost vaccination, and this was associated with significant increases in B lymphocytes, $\mathrm{CD} 14^{+}$monocytes, $\mathrm{CD} 25^{+}$regulatory cells, and $\mathrm{CD}^{+}$cytotoxic $\mathrm{T}$ lymphocytes.

\section{Conflict of Interests}

None of the authors has any financial or personal relationships that could inappropriately influence or bias the content of the paper.

\section{Acknowledgments}

This study was funded by projects BTVAC FP6-2005-SSP-5A and AGL2009-13174-C02-01. A. C. Pérez de Diego holds a scholarship of the FPU programme (Ministry of Education and Science, Spain). P. J. Sánchez-Cordón is supported by a contract of the "Ramón y Cajal programme" (Ministry of Science and Innovation, Spain). The authors thank Amalia for assistance during flow cytometry analysis. They also thank Rocío Sánchez, Belén Rivera, and Pablo del Carmen for dedicating their time and effort to this study.

\section{References}

[1] P. P. C. Mertens, S. Maan, A. Samuel, and H. Attoui, "Orbivirus, reoviridae," in Virus Taxonomy, pp. 466-483, Elsevier/ Academic Press, London, UK, 2004.

[2] V. Chaignat, G. Worwa, N. Scherrer et al., "Toggenburg Orbivirus, a new bluetongue virus: initial detection, first observations in field and experimental infection of goats and sheep," Veterinary Microbiology, vol. 138, no. 1-2, pp. 11-19, 2009.

[3] M. A. Hofmann, S. Renzullo, M. Mader, V. Chaignat, G. Worwa, and B. Thuer, "Genetic characterization of toggenburg orbivirus, a new bluetongue virus, from goats, Switzerland,"
Emerging Infectious Diseases, vol. 14, no. 12, pp. 1855-1861, 2008.

[4] I. Schwartz-Cornil, P. P. C. Mertens, V. Contreras et al., "Bluetongue virus: virology, pathogenesis and immunity," Veterinary Research, vol. 39, no. 5, article 46, 2008.

[5] B. Rodríguez-Sánchez, I. Iglesias-Martín, M. Martínez-Avilés, and J. M. Sánchez-Vizcaíno, "Orbiviruses in the mediterranean basin: updated epidemiological situation of bluetongue and new methods for the detection of BTV serotype 4," Transboundary and Emerging Diseases, vol. 55, no. 5-6, pp. 205-214, 2008.

[6] S. Zientara, N. J. MacLachlan, P. Calistri, J. M. Sanchez-Vizcaino, and G. Savini, "Bluetongue vaccination in Europe," Expert Review of Vaccines, vol. 9, no. 9, pp. 989-991, 2010.

[7] R. Noad and P. Roy, "Bluetongue vaccines," Vaccine, vol. 27, supplement 4, pp. 86-89, 2009.

[8] G. Savini, N. J. MacLachlan, J. M. Sanchez-Vizcaino, and S. Zientara, "Vaccines against bluetongue in Europe," Comparative Immunology, Microbiology and Infectious Diseases, vol. 31, no. 2-3, pp. 101-120, 2008.

[9] G. Ferrari, C. De Liberato, G. Scavia et al., "Active circulation of bluetongue vaccine virus serotype- 2 among unvaccinated cattle in central Italy," Preventive Veterinary Medicine, vol. 68, no. 2-4, pp. 103-113, 2005.

[10] M. Enserink, "Animal disease: exotic disease of farm animals tests Europe's responses," Science, vol. 319, no. 5864, pp. 710$711,2008$.

[11] C. A. L. Oura, J. L. N. Wood, A. J. Sanders et al., "Seroconversion, neutralising antibodies and protection in bluetongue serotype 8 vaccinated sheep," Vaccine, vol. 27, no. 52, pp. 73267330, 2009.

[12] G. Savini, C. Hamers, A. Conte et al., "Assessment of efficacy of a bivalent BTV-2 and BTV-4 inactivated vaccine by vaccination and challenge in cattle," Veterinary Microbiology, vol. 133, no. 1-2, pp. 1-8, 2009.

[13] G. Savini, G. F. Ronchi, A. Leone et al., "An inactivated vaccine for the control of bluetongue virus serotype 16 infection in sheep in Italy," Veterinary Microbiology, vol. 124, no. 1-2, pp. 140-146, 2007.

[14] D. Vitour, J. Guillotin, C. Sailleau et al., "Colostral antibody induced interference of inactivated bluetongue serotype- 8 vaccines in calves," Veterinary Research, vol. 42, no. 1, article 18, 2011.

[15] E. Bréard, G. Belbis, C. Hamers et al., "Evaluation of humoral response and protective efficacy of two inactivated vaccines against bluetongue virus after vaccination of goats," Vaccine, vol. 29, no. 13, pp. 2495-2502, 2011.

[16] M. H. Jeggo, R. C. Wardley, J. Brownlie, and A. H. Corteyn, "Serial inoculation of sheep with two bluetongue virus types," Research in Veterinary Science, vol. 40, no. 3, pp. 386-392, 1986.

[17] M. H. Jeggo, R. C. Wardley, and J. Brownlie, "A study of the role of cell-mediated immunity in bluetongue virus infection in sheep, using cellular adoptive transfer techniques," Immunology, vol. 52, no. 3, pp. 403-410, 1984.

[18] M. Andrew, P. Whiteley, V. Janardhana, Z. Lobato, A. Gould, and B. Coupar, "Antigen specificity of the ovine cytotoxic T lymphocyte response to bluetongue virus," Veterinary Immunology and Immunopathology, vol. 47, no. 3-4, pp. 311-322, 1995.

[19] V. Janardhana, M. E. Andrew, Z. I. P. Lobato, and B. E. H. Coupar, "The ovine cytotoxic T lymphocyte responses to bluetongue virus," Research in Veterinary Science, vol. 67, no. 3, pp. 213-221, 1999. 
[20] J. L. Stott, T. L. Barber, and B. I. Osburn, "Immunologic response of sheep to inactivated and virulent bluetongue virus," American Journal of Veterinary Research, vol. 46, no. 5, pp. 1043-1049, 1985.

[21] A. Perrin, E. Albina, E. Breard et al., "Recombinant capripoxviruses expressing proteins of bluetongue virus: evaluation of immune responses and protection in small ruminants," Vaccine, vol. 25, pp. 6774-6783, 2007.

[22] J. F. Toussaint, C. Sailleau, E. Breard, S. Zientara, and K. De Clercq, "Bluetongue virus detection by two real-time RTqPCRs targeting two different genomic segments," Journal of Virological Methods, vol. 140, no. 1-2, pp. 115-123, 2007.

[23] J. Gethmann, K. Hüttner, H. Heyne et al., "Comparative safety study of three inactivated BTV-8 vaccines in sheep and cattle under field conditions," Vaccine, vol. 27, no. 31, pp. 4118 4126, 2009.

[24] A. Steinrigl, S. Revilla-Fernández, M. Eichinger, J. Koefer, and P. Winter, "Bluetongue virus RNA detection by RT-qPCR in blood samples of sheep vaccinated with a commercially available inactivated BTV-8 vaccine," Vaccine, vol. 28, no. 34, pp. 5573-5581, 2010.

[25] M. Stewart, Y. Bhatia, T. N. Athmaran et al., "Validation of a novel approach for the rapid production of immunogenic virus-like particles for bluetongue virus," Vaccine, vol. 28, no. 17, pp. 3047-3054, 2010.

[26] R. J. Noad, M. Stewart, M. Boyce, C. C. Celma, K. R. Willison, and P. Roy, "Multigene expression of protein complexes by iterative modification of genomic bacmid DNA," BMC Molecular Biology, vol. 10, article 87, 2009.

[27] M. Eschbaumer, R. Wäckerlin, B. Hoffmann, and M. Beer, "Re: detection of bluetongue virus genome after vaccination with an inactivated vaccine," Vaccine, vol. 28 , no. 4, pp. 881-882, 2010.

[28] R. Wäckerlin, M. Eschbaumer, P. König, B. Hoffmann, and M. Beer, "Evaluation of humoral response and protective efficacy of three inactivated vaccines against bluetongue virus serotype 8 one year after vaccination of sheep and cattle," Vaccine, vol. 28, no. 27, pp. 4348-4355, 2010.

[29] M. Eschbaumer, B. Hoffmann, P. König et al., "Efficacy of three inactivated vaccines against bluetongue virus serotype 8 in sheep," Vaccine, vol. 27, no. 31, pp. 4169-4175, 2009.

[30] H. Takamatsu, J. N. Burroughs, A. M. Wade-Evans, and P. P. C. Mertens, "Identification of a Bluetongue virus serotype 1-specific ovine helper T-cell determinant in outer capsid protein VP2," Virology, vol. 177, no. 1, pp. 396-400, 1990.

[31] M. H. Jeggo, R. C. Wardley, and J. Brownlie, "Importance of ovine cytotoxic $\mathrm{T}$ cells in protection against bluetongue virus infection," Progress in Clinical and Biological Research, vol. 178, pp. 477-487, 1985.

[32] B. Hemati, V. Contreras, C. Urien et al., "Bluetongue virus targets conventional dendritic cells in skin lymph," Journal of Virology, vol. 83, no. 17, pp. 8789-8799, 2009.

[33] C. S. Umeshappa, K. P. Singh, A. B. Pandey, R. P. Singh, and R. H. Nanjundappa, "Cell-mediated immune response and cross-protective efficacy of binary ethylenimine-inactivated bluetongue virus serotype-1 vaccine in sheep," Vaccine, vol. 28, no. 13, pp. 2522-2531, 2010.

[34] J. Aucouturier, L. Dupuis, and V. Ganne, "Adjuvants designed for veterinary and human vaccines," Vaccine, vol. 19, no. 1719, pp. 2666-2672, 2001.

[35] E. Iglesias, O. Franch, Y. Carrazana et al., "Influence of aluminum-based adjuvant on the immune response to multiantigenic formulation," Viral Immunology, vol. 19, no. 4, pp. 712 721, 2006.
[36] M. A. Ramakrishnan, A. B. Pandey, K. P. Singh, R. Singh, and M. L. Mehrotra, "Immune response and protective efficacy in sheep immunised with hydroxylamine-inactivated bluetongue virus vaccine," Veterinaria Italiana, vol. 41, pp. 149-155, 2005.

[37] P. Cresswell and A. Lanzavecchia, "Antigen processing and recognition," Current Opinion in Immunology, vol. 13, no. 1, pp. 11-12, 2001.

[38] M. Singh and D. T. O’Hagan, "Recent advances in veterinary vaccine adjuvants," International Journal for Parasitology, vol. 33, no. 5-6, pp. 469-478, 2003.

[39] M. R. Gold, "To make antibodies or not: signaling by the B-cell antigen receptor," Trends in Pharmacological Sciences, vol. 23, no. 7, pp. 316-324, 2002.

[40] I. R. Tizard, "B cells and their response to antigen," in Veterinary Immunology. An Introduction, pp. 152-169, Elsevier Saunders, St. Louis, Mo, USA, 2009.

[41] P. Antal-Szalmás, "Evaluation of CD14 in host defence," European Journal of Clinical Investigation, vol. 30, no. 2, pp. 167$179,2000$.

[42] S. M. Barratt-Boyes, P. V. Rossitto, B. C. Taylor, J. A. Ellis, and N. James MacLachlan, "Response of the regional lymph node to bluetongue virus infection in calves," Veterinary Immunology and Immunopathology, vol. 45, no. 1-2, pp. 73-84, 1995.

[43] P. J. Sánchez-Cordón, B. Rodríguez-Sánchez, M. A. Risalde et al., "Immunohistochemical detection of bluetongue virus in fixed tissue," Journal of Comparative Pathology, vol. 143, no. 1, pp. 20-28, 2010.

[44] J. Zhu and W. E. Paul, "CD4 T cells: fates, functions, and faults," Blood, vol. 112, no. 5, pp. 1557-1569, 2008.

[45] R. Bujdoso, B. T. Lund, C. W. Evans, and I. McConnell, "Different rates of interleukin 2 receptor expression by ovine $\gamma / \delta$ and $\alpha / \beta$ T cells," Veterinary Immunology and Immunopathology, vol. 39, no. 1-3, pp. 109-114, 1993.

[46] J. A. Ellis, A. J. Luedke, W. C. Davis et al., “T lymphocyte subset alterations following bluetongue virus infection in sheep and cattle," Veterinary Immunology and Immunopathology, vol. 24, no. 1, pp. 49-67, 1990. 

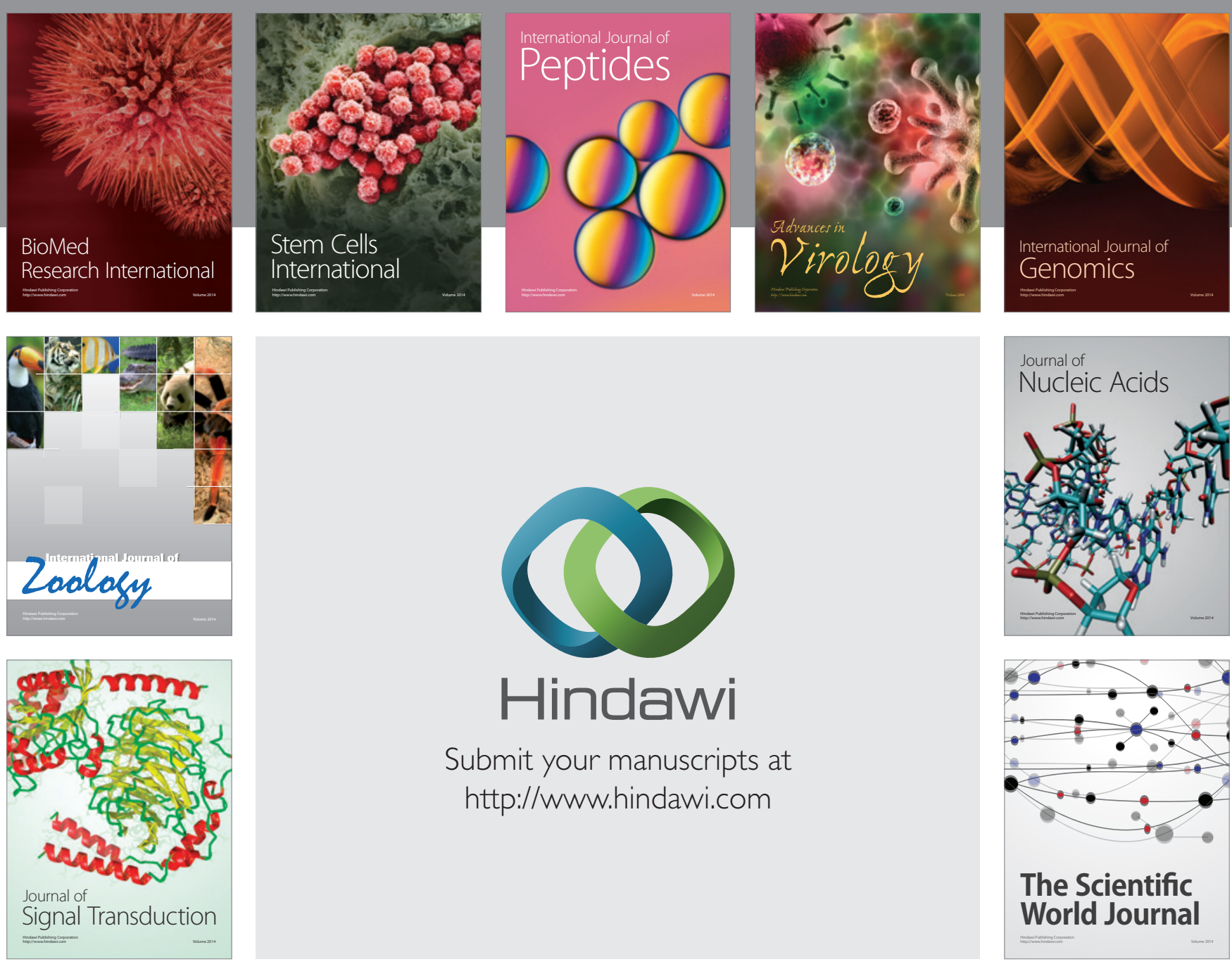

Submit your manuscripts at

http://www.hindawi.com
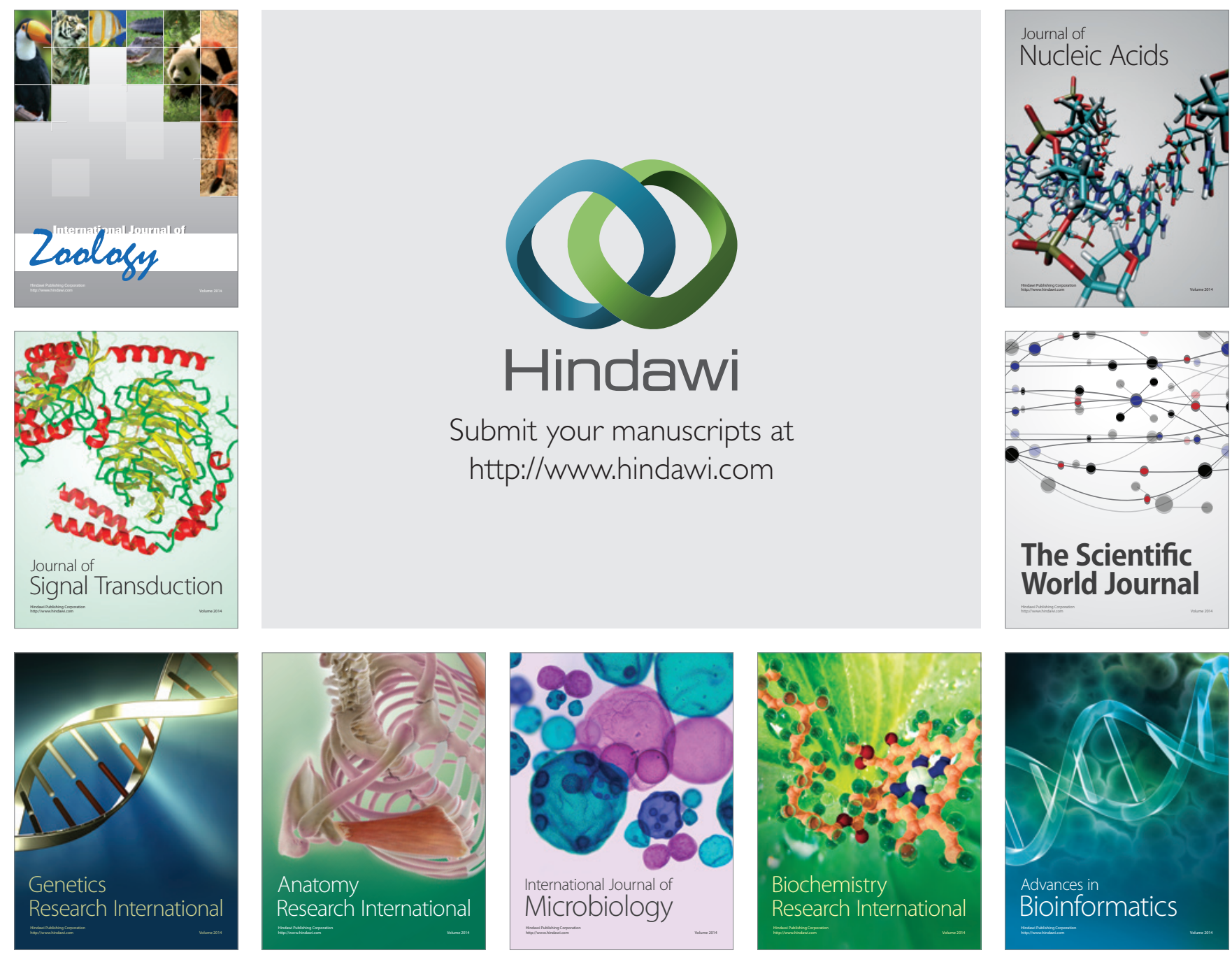

The Scientific World Journal
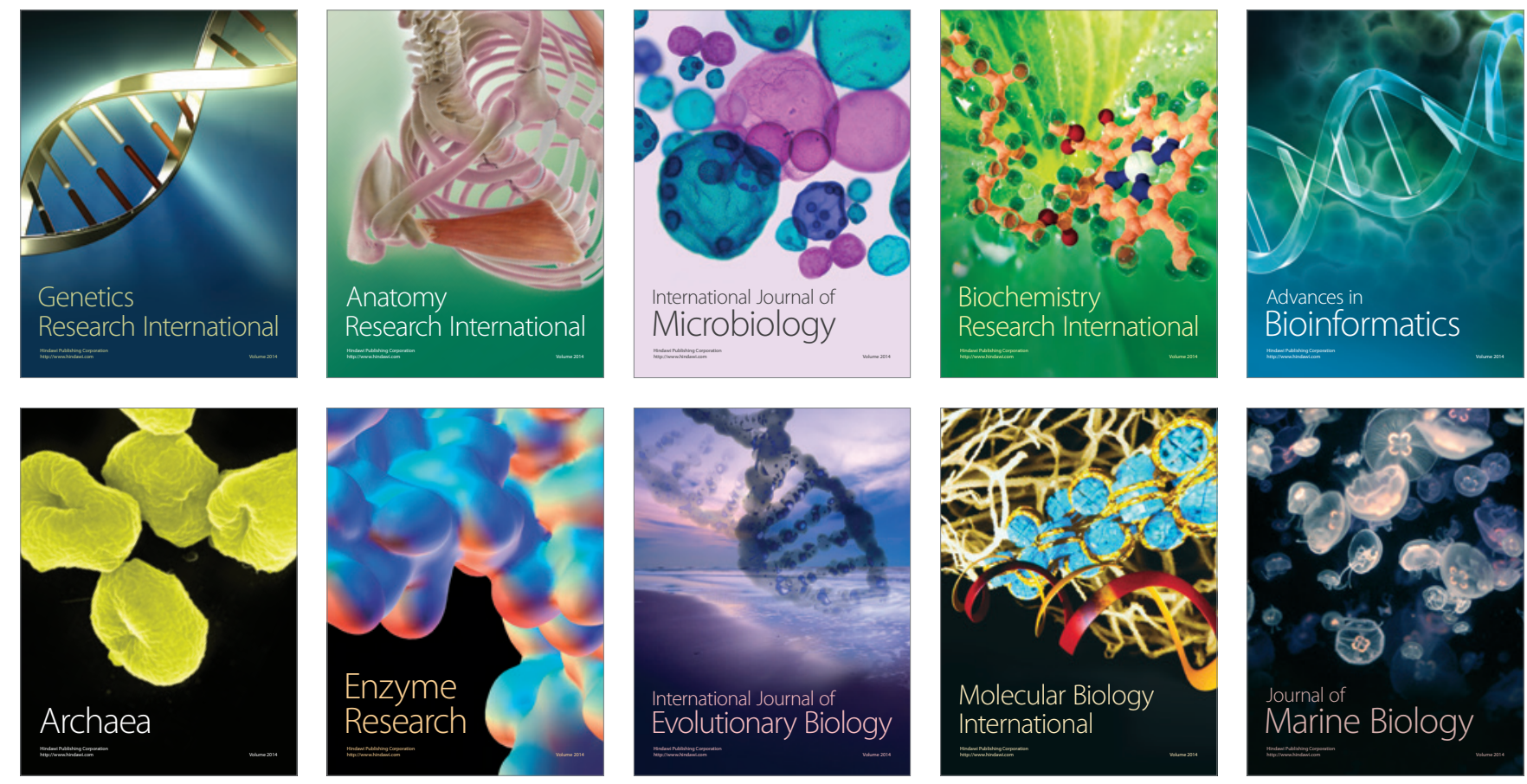